\title{
The Prevalence of Prediabetes in Healthcare Professionals assessed based on Glycated Hemoglobin Levels
}

Witold Rongies $^{1,2}$, Monika Wolska ${ }^{3}$, Katarzyna Strzałka-Goc ${ }^{4}$, Bartosz Słomka ${ }^{1^{\star}}$, Przemysław Krasnodębski ${ }^{5}$, Włodzimierz Dolecki ${ }^{5}$ and Krzysztof Dembe $^{5}$

${ }^{1}$ Department of Physiotherapy, Rehabilitation Division, II Faculty of Medicine, Medical University of Warsaw, Poland

${ }^{2}$ Department of Rehabilitation, Independent Public Central Clinical Hospital in Warsaw, Poland

${ }^{3}$ Medical University of Warsaw, Poland

${ }^{4}$ Center of Rehabilitation Constance Care Konstancin, Poland

${ }^{5}$ Department of Internal Diseases and Diabetology, Medical University of Warsaw, Poland

"Corresponding author: Bartosz S, Department of Physiotherapy, Rehabilitation Division, II Faculty of Medicine, Medical University of Warsaw, Poland, Tel: +48508 391 725; E-mail: bartosz.slomka@wum.edu.pl

Rec date: Feb 29, 2015; Acc date: Mar 17, 2015; Pub date: Mar 25, 2015

Copyright: (c) 2016 Rongies W, et al. This is an open-access article distributed under the terms of the Creative Commons Attribution License, which permits unrestricted use, distribution, and reproduction in any medium, provided the original author and source are credited.

\section{Abstract}

Background: Due to its significant prevalence, incidence, and economic burden, type 2 diabetes mellitus has been the subject of a number of economic analyses and epidemiological studies. It is believed that it may take as many as 12 years from the onset of the first sign of type 2 diabetes mellitus to the time of diagnosis. Thus, there is a potential benefit in conducting screening tests in the interim to help detect prediabetes before type 2 diabetes mellitus fully develops.

Objective: To assess the risk of type 2 diabetes mellitus in a randomly selected group of healthcare professionals employed at one of Warsaw hospitals by measuring glycated hemoglobin levels with the A1cNow+ test.

Materials and methods: The study included 465 employees of the Independent Public Central Hospital in Warsaw. The selection of healthcare professionals for the study was random. Inclusion criteria: healthcare professionals employed at the Independent Public Central Hospital in Warsaw; no awareness of having type 2 diabetes mellitus. The largest study subgroup (63.4\%) were nurses, followed by physicians $13.5 \%$, physiotherapists $(10.3 \%)$, and orderlies (6.6\%). All subjects underwent glycated hemoglobin level measurement with the Bayer $\mathrm{A} 1 \mathrm{cNow}+$ system. The statistical analysis was conducted with Statistica 10.0. Apart from this, Mann-Whitney's U test, Kruskal-Wallis's test (post hoc Dunn's test), Spearman's rank correlation coefficient and test for significance. The adopted significance level was $\alpha=0.05$.

Results: The study group was evaluated for metabolic disturbances (expressed in the form of HbA1c levels) with an American Diabetes Association-approved classification. The results indicated that a vast majority of the evaluated healthcare personnel (383 people; $82.4 \%$ ) had normal glycated hemoglobin levels. The remainder of the study group showed carbohydrate metabolism disturbances. The range of glycated hemoglobin levels (5.7-6.4\%) found in 73 people $(15.7 \%)$ suggested an increased risk for diabetes. As a result of the study, as few, or as many, as 9 people $(1.9 \%)$ were diagnosed with diabetes (initial diagnosis).

Conclusions: Most of the evaluated healthcare professionals (82.4\%) showed no evidence of being at risk for type 2 diabetes mellitus. Only $17.6 \%$ of respondents were unaware of their metabolic disturbances. The study demonstrated a positive correlation between body mass index values and glycated hemoglobin levels in the evaluated group of healthcare professionals $(R=0.3)$, which was similar to that found in the general population.

Keywords: HbAlc; AlcNow+ test; Diabetes mellitus; Glucose; Health care; Screening; Health care workers

\section{Introduction}

Type 2 diabetes mellitus (T2DM) is one of the main medical problems in a number of countries in the world, both in terms of its socioeconomic and healthcare impact. T2DM may remain asymptomatic for a long time, which means it is often diagnosed only when severe complications have already developed. At present, nearly $50 \%$ of patients have at least one complication before being diagnosed. T2DM imposes a number of limitations on the patient's lifestyle, sometimes leading to disability and sometimes - to premature death. Due to its significant prevalence, incidence, and economic burden,
T2DM has been the subject of many economic analyses and epidemiological studies. It is believed that it may take as many as 12 years from the onset of T2DM to the moment the diagnosis is established. Thus, there is a potential benefit in conducting screening tests in the interim to help detect prediabetes before T2DM fully develops. Such a screening test should be brief, not inconvenient for the patient, and highly accurate. Bearing in mind that screening tests are not always conclusive, they are still worth conducting, as they suggest the direction for further diagnostics. Another important element of diabetes prevention, especially T2DM, is health-oriented education of the general public. This is implemented largely by family doctors. However, considering the extent of the need for public education in this field, the help of other healthcare professionals, who are also able to initiate preventive measures and detect the first signs 
and symptoms of carbohydrate metabolism disturbances, must be sought. In light of the above, we aimed to assess, in an indirect and practical manner, the knowledge on T2DM in various groups of healthcare professionals by measuring glycated hemoglobin $(\mathrm{HbA1c})$ levels in 465 employees of one of Warsaw hospitals [1-7].

\section{Objective}

The study aimed to assess the risk of T2DM in a randomly selected group of healthcare professionals at one of Warsaw hospitals by measuring HbAlc levels with the AlcNow+ test (Bayer HealthCare).

\section{Material and Methods}

The study group comprised 465 healthcare professional employees of the Independent Public Central Hospital (SP CSK) in Warsaw. The recruited subjects were selected randomly. Each subject had to meet the following inclusion criteria: being a healthcare professional employed at SP CSK in Warsaw; having no awareness of suffering from T2DM.

The most numerous study subgroup $(\mathrm{n}=295)$ were nurses, who constituted $63.4 \%$ of the entire study group. The second most numerous subgroup $(\mathrm{n}=63)$ were physicians at $13.5 \%$, followed by physiotherapists $(n=48 ; 10.3 \%)$ and orderlies $(n=30 ; 6.6 \%)$. The least numerous subgroup $(\mathrm{n}=29 ; 6.2 \%)$ comprised "other healthcare professionals," such as medical receptionists and medical secretaries.

The study group included 398 women (85.6\%) and 67 men (14.4\%). Age data were grouped into 5 ranges, with the largest subgroup (28.2\%) aged $40-49$ years, followed by $50-59$ years (27.7\%) and $20-29$ years $(20.6 \%)$, and the smallest subgroup $(3 \%)$ aged $\geq 60$ years.

\section{Study design}

The study protocol was approved by the Institutional Review Board at the Medical University of Warsaw on May 7, 2013 (KB/152/2013). The study period was from May to December 2013. Each subject was informed of the objectives, methods, benefits, possible discomforts, and other important aspects of the study. All subjects who provided written informed consent underwent testing of HbAlc levels with the use of the Bayer HealthCare AlcNow+ system. Subsequently, all subjects completed a questionnaire on their anthropometric data (weight, height) and information on their medical profession. Only fully and correctly completed questionnaires were included in the analysis.

\section{Measuring HbA1c levels with the Bayer A1cNow+ system}

Glycated hemoglobin (HbAlc) is a product of non-enzymatic protein glycation and the quantity formed depends on the amount of the available substrates: blood hemoglobin A and blood glucose. $\mathrm{HbAlc}$ is produced continuously throughout the lifespan of a red blood cell, which is approximately 120 days. HbAlc levels are proportional to those of serum glucose. Thus, HbA1c testing can help retrospectively assess the average serum glucose levels in the period of up to 2-3 months prior to the test. HbAlc is considered to be an excellent test parameter and $\mathrm{HbAlc}$ testing is an established standard of assessment in diabetic patient monitoring [1-3]. Novel technical solutions employed in the Bayer AlcNow+ system help measure HbAlc levels either in venous or capillary blood. The Bayer HealthCare AlcNow+ system, which was designed for rapid and accurate HbAlc testing, meets the National Glycohemoglobin
Standardization Program (NGSP) requirements. Moreover, the obtained results can be interpreted based on the International Federation of Clinical Chemistry and Laboratory Medicine (IFCC) standard. Results obtained with the HbAlc measuring system used in this study have been shown to be highly consistent (approximately 99\%) with those obtained via a reference method [3].

Our assessments involved $5 \mu \mathrm{l}$ samples of capillary or venous blood collected via a fingertip prick with a disposable lancet. Each test was conducted with a disposable kit opened directly in front of the subject immediately prior to blood sample collection. Each collected blood sample was placed in a Alc Now+ system capillary tube, which initiated the $\mathrm{HbAlc}$ level measurement. Test results were ready 5 minutes later. The obtained $\mathrm{HbAlc}$ level values were analyzed according to American Diabetes Association (ADA) guidelines. The findings served as the basis for assessing the risk of diabetes. Diabetes mellitus was diagnosed if $\mathrm{HbAlc}$ levels were equal to or greater than $6.5 \%$. Subjects with $\mathrm{HbAlc}$ levels in the $5.7-6.4 \%$ range were considered to be at high risk for diabetes (Table 1) [2-12].

\begin{tabular}{|l|l|l|}
\hline HbA1c levels (criteria) & $\begin{array}{l}\text { Study group } \\
(\mathbf{n = 4 6 5 )}\end{array}$ & $\%$ \\
\hline Normal<5.7\% & 383 & $82.4 \%$ \\
\hline at risk for diabetes $5.7-6.4 \%$ & 73 & $15.7 \%$ \\
\hline diagnosed with diabetes $\geq 6.5 \%$ & 9 & $1.9 \%$ \\
\hline
\end{tabular}

Table 1: Diabetes risk classification (according to ADA) based on HbA1c levels.

A $1 \%$ change in $\mathrm{HbAlc}$ corresponds to a mean change in blood glucose levels by approximately $30 \mathrm{mg} / \mathrm{dl}$. Rising serum glucose levels and long-term hyperglycemia lead to an increase in HbAlc levels. These unfavorable changes closely correlate with higher risk for early and long-term diabetes complications [2].

\section{Statistical Analysis}

The statistical analysis was conducted with Statistica 10.0. We conducted a descriptive analysis of study results. The subsequent Shapiro-Wilk test revealed non-normal data distribution. The next step involved the use of non-parametric tests (Friedman's ANOVA and Wilcoxon's tests) for dependent variables. The Spearman correlation test was used to demonstrate correlations between the evaluated variables. The chi-square test for independence was used to assess the relationship between qualitative variables. In all analysis the 0.05 significance level was assumed. Qualitative variables were presented as absolute values and percent values in reference to the total study group.

\section{Results}

The mean age in the study group was $42.1 \pm 11.3$ years. The differences between the first quartile and minimum values and between the maximum and third quartile values were 10 and 24, respectively. This demonstrated the age distribution to be skewed to the right. The mean age was lower than the median, which meant that more than a half of subjects were at an age above the mean value.

The body mass index (BMI) was also evaluated. Twelve respondents, which constituted $2.6 \%$ of all the randomly selected healthcare professionals undergoing evaluation, were underweight. A total of 239 subjects (51.4\%) exhibited normal body weight (within normal limits), 
Citation: Rongies, Wolska M, Strzalka-Goc K, Slomka B, Krasnodebski P, et al. (2016) The Prevalence of Prediabetes in Healthcare Professionals assessed based on Glycated Hemoglobin Levels. J Diabetes Metab 7: 660. doi:10.4172/2155-6156.1000660

Page 3 of 5

137 (29.5\%) were overweight, and 77 (16.6\%) were obese. The minimum BMI value in the study group was $16.7 \mathrm{~kg} / \mathrm{m}^{2}$, and the maximum $44.2 \mathrm{~kg} / \mathrm{m}^{2}$ (mean $25.4 \pm 4.5 \mathrm{~kg} / \mathrm{m}^{2}$, median $24.6 \mathrm{~kg} / \mathrm{m}^{2}$ ). The first and third quartile BMI values were $22.2 \mathrm{~kg} / \mathrm{m}^{2}$ and 27.7 $\mathrm{kg} / \mathrm{m}^{2}$, respectively. Like in the case of age, BMI values also showed a decidedly right-skewed distribution.

The study group was evaluated for metabolic disturbances (expressed in the form of $\mathrm{HbAlc}$ levels) with an ADA-approved classification. The results indicated that a vast majority of the evaluated healthcare personnel (383 people; 82.4\%) had normal HbAlc levels. The remainder of the study group showed carbohydrate metabolism disturbances. The range of HbAlc levels (5.7-6.4\%) found in 73 people (15.7\%) suggested an increased risk for diabetes. As a result of the study, as few, or as many, as 9 people (1.9\%) were diagnosed with diabetes (initial diagnosis) (Table 1).

The maximum, mean, and minimum $\mathrm{HbAlc}$ levels in the evaluated healthcare professionals were $9.6 \%, 5.4 \%$, and $4.1 \%$ respectively. The median and mean values differed only by $0.1 \%$. Quartile values and their respective extremes were: 1 for the minimum and 4 for the maximum, which indicated a right skewed distribution. HbAlc levels showed a lesser variance than other analyzed parameters.

The statistical analysis also included the assessment of any possible effect the individual healthcare professions had on the evaluated variables (age, BMI, HbAlc level). The study group was stratified by the profession and each of these subgroups was individually tested for normality.

This analysis showed normal distribution for all of these variables only in the group of hospital orderlies. Because of the results and the number of professions evaluated, data comparisons were conducted with the Kruskal-Wallis test.

\section{Other medical personnel (medical receptionists and secretaries)}

The mean age in this subgroup was $39 \pm 11.1$ years, with the youngest person 26 and the oldest one 60 years old. The maximum, mean, and minimum $\mathrm{HbA} 1 \mathrm{c}$ levels in this subgroup were $6.2 \%, 5.3 \%$, and $4.7 \%$, respectively, while BMI values were $43 \mathrm{~kg} / \mathrm{m}^{2}, 25.2 \mathrm{~kg} / \mathrm{m}^{2}$, and $16.4 \mathrm{~kg} / \mathrm{m}^{2}$ respectively (Table 2 ).

The maximum, mean, and minimum $\mathrm{HbAlc}$ levels were $9 \%, 5.4 \%$, and $4.1 \%$ respectively, while BMI values were $44.2 \mathrm{~kg} / \mathrm{m}^{2}, 25.6 \mathrm{~kg} / \mathrm{m}^{2}$, and $17.6 \mathrm{~kg} / \mathrm{m}^{2}$ respectively (Table 2 ).

\section{Nurses}

The mean age of nurses was $41.8 \pm 11.2$ years, with the youngest person aged 21 and the oldest one 65 years.

\begin{tabular}{|c|c|c|c|c|c|c|c|c|c|c|}
\hline \multirow{3}{*}{ Variables } & \multicolumn{2}{|c|}{ Physiotherapist Group } & \multicolumn{2}{|c|}{ Physician Group } & \multicolumn{2}{|l|}{ Nurse Group } & \multicolumn{2}{|c|}{ Hospital Orderlies } & \multicolumn{2}{|c|}{ Other Medical Personnel } \\
\hline & $(n=48)$ & & $(n=63)$ & & $(n=295)$ & & $(n=30)$ & & $(n=29)$ & \\
\hline & Mean $\pm S^{*}$ & Range & $\begin{array}{ll}\text { Mean } & \pm \\
\text { SD }^{*} & \end{array}$ & Range & Mean $\pm S^{*}$ & Range & Mean \pm SD $^{*}$ & Range & Mean $\pm \mathrm{SD}^{*}$ & Range \\
\hline Age $(y r)$ & $44.8 \pm 11.2$ & $26-59$ & $42.1 \pm 12.1$ & $25-75$ & $41.8 \pm 11.2$ & $21.0-65.0$ & $44.2 \pm 10.2$ & $21.0-58.0$ & $39.0 \pm 11.1$ & $26-60$ \\
\hline BMI (Kg/m2) & $24.1 \pm 2.4$ & 20.3-33.3 & $25.1 \pm 3.8$ & $17.2-33.06$ & $25.6 \pm 4.6$ & $17.6-44.2$ & $26.2 \pm 5.3$ & $16.7-38.9$ & $25.2 \pm 6.4$ & $16.4-43$ \\
\hline $\mathrm{HbA1c}(\%)$ & $5.3 \pm 0.3$ & $4.8-6.5$ & $5.5 \pm 0.9$ & $4.6-9.6$ & $5.4 \pm 0.5$ & $4.1-9.0$ & $5.4 \pm 0.3$ & $4.9-6.0$ & $5.3 \pm 0.3$ & $4.7-6.2$ \\
\hline
\end{tabular}

Table 2: Descriptive statistics in the study groups.

\section{Hospital orderlies}

The mean age of orderlies was $44.2 \pm 10.2$ years, with the youngest person aged 21 and the oldest one 58 years. The maximum, mean, and minimum $\mathrm{HbAlc}$ levels in this group were $6.0 \%, 5.4 \%$, and $4.9 \%$, respectively, while BMI values were $38.9 \mathrm{~kg} / \mathrm{m}^{2}, 26.2 \mathrm{~kg} / \mathrm{m}^{2}$, and $16.7 \mathrm{~kg} / \mathrm{m}^{2}$ respectively (Table 2 ).

\begin{tabular}{|l|l|l|l|}
\hline Profession & $\mathbf{n}$ & Mean & \multirow{2}{*}{ p-value } \\
\hline Physiotherapist & 48 & 44.8 & \\
\cline { 1 - 3 } Physician & 63 & 42.1 & \multirow{2}{*}{0.119} \\
\cline { 1 - 3 } Nurse & 295 & 41.8 & \\
\hline Hospital orderlies & 30 & 44.2 & \\
\hline Other personnel & 29 & 39 & \\
\hline
\end{tabular}

Table 3: A comparison of healthcare profession subgroups in terms of age (in years).
Physiotherapists had the highest mean age out of all the evaluated healthcare professionals. The statistical analysis showed no significant differences between subgroups in terms of age $(p=0.119)$ (Table 3). Orderlies had the highest mean BMI value. The statistical analysis showed no statistically significant differences between the healthcare professional subgroups in terms of BMI $(\mathrm{p}=0.261)$ (Table 4$)$.

\begin{tabular}{|l|l|l|l|}
\hline Profession & $\mathbf{n}$ & Mean & \multirow{2}{*}{ p-value } \\
\hline Physiotherapist & 48 & 24.1 & \multirow{2}{*}{0.261} \\
\cline { 1 - 3 } Physician & 63 & 25.1 & \\
\cline { 1 - 3 } Nurse & 295 & 25.6 & \\
\hline Orderly & 30 & 26.2 & \\
\hline Other personnel & 29 & 25.2 & \\
\hline
\end{tabular}

Table 4: A comparative analysis of the evaluated healthcare profession subgroups in terms of BMI $\left(\mathrm{kg} / \mathrm{m}^{2}\right)$. 
Mean $\mathrm{HbAlc}$ levels were similar in all healthcare professional subgroups. The highest $\mathrm{HbAlc}$ level was observed in the physician group and the lowest in the nurse group. The analysis showed no differences between the evaluated medical professions in terms of HbAlc levels ( $\mathrm{p}=0.904)$ (Table 5).

\begin{tabular}{|l|l|l|l|}
\hline Profession & $\mathbf{n}$ & Mean & p-value \\
\hline Physiotherapist & 48 & 5.3 & \\
\hline Physician & 63 & 5.5 & \\
\hline Nurse & 295 & 5.4 & \multirow{2}{*}{0.904} \\
\cline { 1 - 2 } Orderly & 30 & 5.4 & \\
\cline { 1 - 2 } Other personnel & 29 & 5.3 & \\
\hline
\end{tabular}

Table 5: A comparative analysis of the evaluated healthcare professional subgroups in terms of HbAlc levels (\%).

\section{Discussion}

The delay in diagnosing T2DM is a significant problem of modern medicine. T2DM may be asymptomatic for many years. Therefore, it is often detected incidentally during routine diagnostic evaluations $[3,13]$. Considering the high cost of treatment, which is mostly due to diabetic complications, it seems necessary to introduce preventive programs [14].

Promoting a "healthy lifestyle" should be the primary objective of public healthcare. Health-oriented behavior of people in certain professions, especially healthcare, should serve as an example for the general population. The use of primary prevention (e.g. lifestyle changes, eliminating risk factors for diabetes) would likely contribute to limiting epidemiological increase in T2DM prevalence. Public awareness and health-related knowledge play an essential role in this respect. Based on this study, healthcare professionals seem to have extensive knowledge and awareness in the field of "a healthy lifestyle" [15-17]. Healthcare professionals should exhibit behaviors reflecting their health awareness; however, the reality is often quite different. There have been few studies in this professional group. This may be due to the fact that lifestyles of healthcare professionals are associated with high physical and psychological stress and limited free time [16] This may be responsible for this professional group's reluctance to participate in studies and, consequently, the scarcity of research on this part of the population.

The main aim of this study was to assess the risk of T2DM in different professions by analyzing randomly selected healthcare professionals employed at SP CSK in Warsaw. The study group evaluated in terms of two parameters: the rates of metabolic disturbances (expressed in terms of HbAlc levels) and body weight abnormalities as one of the key risk factors for T2DM. The first parameter was evaluated via a diabetes screening test based on assessing glycated hemoglobin with the Bayer HealthCare AlcNow+ system. The results were analyzed according to ADA's criteria. The adopted cutoff $\mathrm{HbA1c}$ level indicating diabetes was $\geq 6.5 \%$, whereas HbAlc levels of $5.7-6.4 \%$ marked a high risk of diabetes. A vast majority of subjects (82.4\%) had normal HbAlc levels. High risk of diabetes was detected in 73 subjects $(15.7 \%)$, while only $1.9 \%$ of subjects met diagnostic criteria for diabetes. Comparing the results demonstrated by the evaluated healthcare professionals with those shown as part of a multicenter trial in the Polish population, we can see significant differences.

As much as $32.2 \%$ of subjects participating in the multicenter study by Franek et al. conducted in the Polish population was at risk for diabetes, whereas metabolic disturbances (expressed with $\mathrm{HbAlc}$ levels) were present in $6.6 \%$ of the study population [1]. Our study showed no statistically significant differences between the male and female groups in terms of $\mathrm{HbAlc}$ levels. The study also demonstrated non-significant differences in $\mathrm{HbAlc}$ levels between the individual healthcare professional groups. However, consistently with physiology of the aging process and the increase in weight, $\mathrm{HbAlc}$ levels were shown to have a positive correlation with age (Table 6). Older people may be more overweight, have more insulin resistance, and consequently - higher $\mathrm{HbAlc}$ levels. A similar situation can be observed in the case of $\mathrm{HbAlc}$ level and BMI correlation. Higher BMI values tend to be associated with higher insulin resistance and higher blood glycose levels. This means that increasing age and BMI values are accompanied by increasing values of glycated hemoglobin.

\begin{tabular}{|l|l|l|l|}
\hline A pair of variables & $\mathbf{n}$ & $\mathbf{r}$ & p-value \\
\hline HbA1c vs age & 465 & 0.36 & 0 \\
\hline HbA1c vs BMI & 465 & 0.30 & 0 \\
\hline
\end{tabular}

"HbA1c: Glycated hemoglobin; BMI: Body mass Index; r: value of Spearman's rank correlation

Table 6: The influence of age and BMI on HbAlc in the group of medical workers.

Our independent research also addressed the overweight and obesity rates in the evaluated population of healthcare professionals. Higher-than-normal body weight has been progressively observed in the Polish population for the last several years. A similar tendency has been reported in other countries, especially highly developed ones. Reports based on nationwide Polish studies conducted as part of the following programs: NATPOL PLUS, WOBASZ, and "Household Food Consumption and Anthropometric Survey," demonstrated the rates of excessive weight in the Polish society. Excessive weight was reported in nearly $60 \%$ of adult men and nearly $50 \%$ of adult women. Overweight was more common in men (39-41\%) than in women (28-29\%). When it comes to obesity, the proportion of obese men was $16-21 \%$ and that of obese women was $19-22 \%$ [18]. The same classification of excessive body weight was used in our study. This was done to help compare the data collected from the healthcare personnel to that from the Polish population. The study conducted in healthcare personnel at SP CSK in Warsaw revealed $51.4 \%$ of subjects to have normal BMI values. Overweight was observed in $29.5 \%$ of subjects and obesity in $16.6 \%$. Like in Polish nationwide studies, in our study BMI values in men were higher than those in women. The observed differences in BMI values between the individual professional groups were not statistically significant. Thus, we can say that our study ensured the evaluated, randomly selected groups to be homogeneous and comparable.

The results of our study indicated a need for active efforts to identify people with prediabetes or undiagnosed diabetes. The study also emphasized the problem of overweight and obesity (which requires instituting appropriate behavioral management), present also among healthcare professionals. 
Citation: Rongies, Wolska M, Strzalka-Goc K, Slomka B, Krasnodebski P, et al. (2016) The Prevalence of Prediabetes in Healthcare Professionals assessed based on Glycated Hemoglobin Levels. J Diabetes Metab 7: 660. doi:10.4172/2155-6156.1000660

Page 5 of 5

\section{Conclusions}

Most of the evaluated healthcare professionals demonstrated a good knowledge of the signs and symptoms of T2DM. Only $17.6 \%$ of respondents were unaware of their metabolic disturbances.

Slightly over half $(51.4 \%)$ of the study group had normal BMI values, which does not give much credit to the preventive awareness in the evaluated healthcare group. One in three respondents (29.5\%) were overweight and $16.6 \%$ of respondents were obese.

The study demonstrated a positive correlation between BMI values and HbAlc levels in the evaluated group of healthcare professionals $(\mathrm{R}=0.3)$, which was similar to that found in the general population. The study revealed no correlation between the presence of metabolic disturbances (expressed as glycated hemoglobin levels) and the type of medical profession.

\section{Acknowledgment}

We would like to thank all participants who participated in this work. We would like to express our appreciation to our colleagues and nurses at Independent Public Central Clinical Hospital in Warsaw (SP CSK) who facilitated this work. At last but not least, I'd like to thank all the members of the Editorial Advisory Board for their careful review.

\section{Location of the Study and Ethics Approvals}

The study was conducted at the Independent Public Central Clinical Hospital in Warsaw, Poland. The project was approved by Ethics and Research Review Committee of Medical University of Warsaw.

\section{References}

1. Towpik I, Gronkowska E, Jedynasty K, Krauchuk A, Lipka J, et al. (2012) Glycated hemoglobin for diagnosis of diabetes in polish population of more than 45 years of age - a multicenter study. Clinical Diabetology 1: 131-137.

2. Potyralska M, Sojka E, Strojek K (2011) HbA1c levels as tool for diagnosing diabetes. Clinical Diabetology 12: 202-209.

3. Potyralska M, Strojek K (2014) Evaluation of the usefulness of HbAlc measurement for diagnosing diabetes in a selected sample of the Polish population. Clinical Diabetology 3: 51-56.
4. American Diabetes Associaton (2010) Standards of Medical Care in Diabetes 2010. Diabetes Care 33: 11-69.

5. Herman WH, Cohen RM (2012) Racial and Ethnic Differences in the Relationship between HbA1c and Blood Glucose: Implications for the Diagnosis of Diabetes. J Clin Endocrinol Metab 97: 1067-1072.

6. Shaw JE, Sicree RA, Zimmet PZ (2010) Global estimates of the prevalence of diabetes for 2010 and 2030. Diabetes Res Clin Pract 87: 4-14.

7. Unwin N, Gan D, Whiting D (2010) The IDF diabetes atlas: providing evidence, raising awareness and promoting action. Diabetes Res Clin Pract 87: 2-3.

8. Czupryniak L, Grzeszczak W, Gumprecht J ( 2009) Improvement of the type 2 diabetes management - role of the innovative therapies taking DPP-4 inhibitors as an example. Clinical Diabetology 10: 7-20.

9. Davies M, Gill J, Gray L, Webb D, Henson J, et al. (2010) Levels of physical activity and relationship with markers of diabetes and cardiovascular disease risk In 5474 white European and South Asian adults screened for type 2 diabetes. Prev Med 51: 290-294.

10. Mazzola N (2012) Review of current and emerging therapies in type 2 diabetes mellitus. Am J Manag Care 18: 17-26.

11. Nawroth P, Pfeiffer M, Von Bauer R (2011) The new puzzle about the treatment of type 2 diabetes after the ACCORD and Da Qing studies. Langenbecks Arch Surg 396: 941-947.

12. Orłowska-Kunikowska E (2010) ADA Clinical Practice Recommendations for Diabetes for the 2010. What's new? Clinical Diabetology 11: 64-68.

13. Diabetes - The hidden pandemic of (2013) PFED News Education Galleries Contact.

14. Czech A (2010) Urgent need for prevention in the practice of sociomedical care for people with type 2 diabetes world and Poland. Metabolic Medicine 14: 10-15.

15. Bergier J, Bergier B, Soroka A, Kubińska Z (2010) Physical activity among nurses with consideration of their age. General Medicine 16: 595-605.

16. Bergier J, Pocztarska-Dec A (2012) Physikal activities of health care workers in the light of natiolal survey. Human and Health 6: 138-142.

17. Biernat E, Gajewska A, Poznańska A (2012) Is physical activity of medical personnel a role model for their patients. Ann Agric Environ Med 19: 707-710.

18. Gajewska M, Gorynski P, Wysocki M (2011) Obesity and type 2 diabetes as main causes of hospitalization in Polish hospitals in 2008. Probl Hig Epidemiol 92: 132-136. 